\title{
Internet-based Spousal Communication during Deployment: Does it Increase Post-deployment Marital Satisfaction?
}

\author{
Warren N. Ponder \\ Regina T. P. Aguirre
}

\begin{abstract}
The purpose of this study was to explore the question: Is a service member's post-deployment marital satisfaction correlated with frequency and mode of communication during deployment? This study used an anonymous exploratory design with a sample of 119 Operation Iraqi Freedom (OIF) or Operation Enduring Freedom (OEF) married veterans. Service members who communicated daily during deployment with their spouses had higher marital satisfaction scores than those who communicated less than once per week. Additionally, participants who used US mail had the highest marital satisfaction scores compared to telephone and internet-based communication. This study expands the overwhelmingly qualitative current literature to include quantitative analysis of this topic. This study also depicts the veterans' experiences since many of the previous studies of this topic used samples of spouses.
\end{abstract}

Keywords: Communication, marital satisfaction, Veteran, Operation Iraqi Freedom (OIF), Operation Enduring Freedom (OEF)

\section{INTRODUCTION}

Being able to stay connected to loved ones has been a top priority for military personnel for generations with both military and non-profit organizations allocating resources to aid soldiers in using all modes of communication available. During World War I (WWI) and World War II (WWII), soldiers' primary mode of communication was the US mail (Schumm, Bell, Ender, \& Rice, 2004). During WWII soldiers were frustrated with the long wait times associated with receiving mail (Applewhite, \& Segal, 1990; Bell, Schumm, Knott, \& Ender, 1999; Stouffer, Suchman, DeVinney, Star, \& Williams, 1949). The Military Auxiliary Radio System (MARS) was used during the Korean and Vietnam wars allowing service members faster communication time with their loved ones (Schumm, et al., 2004). During Operation Desert Storm (ODS) fax, e-mail, videotapes, US mail, audiotapes, and teleconferences where available to some of the deployed personnel (Ender \& Segal, 1990; Schumm, et al., 2004). During Operation Joint Endeavor (Bosnia), Operation Restore Hope (Somalia), and Operation Uphold Democracy (Haiti), email, telephone and sometimes teleconferencing were available (Schumm et al., 2004).

In the present wars, Operation Iraqi Freedom (OIF) and Operation Enduring Freedom (OEF), military personnel have the most modern forms of communication at their fingertips. Whereas in previous wars US mail was the only mode of communication, service members now can communicate with their loved ones over such media as telephone, email, instant messenger/message board, video, and webcam (Merolla, 2010), increasing frequency and immediacy of communication. Access to much of the modes of

\footnotetext{
Warren N. Ponder, LMSW, ACSW is a social worker for the Readjustment Counseling Service, Department of Veterans Affairs, Fort Worth, TX. Regina T. P. Aguirre, Ph.D., LMSW-AP is an Assistant Professor at The University of Texas at Arlington School of Social Work.
}

Copyright (C) 2012 Advances in Social Work Vol. 13 No. 1 (Spring 2012), 216-228 
communication is provided by the military with non-profits assisting with items such as telephone calling cards and cell phones. Little is known about the impact that these additional communication modes have on the marital relationship after deployment. The purpose of the current study is to determine if a service member's post-deployment marital satisfaction is correlated with the frequency and mode of communication during deployment.

\section{Theoretical Framework}

Many theories exist about marital satisfaction covering a broad spectrum of aspects that impact satisfaction including employment, communication, adoption, and stress. For the purposes of this study, the two theories discussed are related to stressful events and are focused on the uniqueness of the military couples' experiences. A long-standing theory of marital satisfaction in the face of life-stressors is Hill's (1958) ABC-X Model in which he attempted to address how (A) an event or stressor and (B) the family's resources or strengths led to $(\mathrm{C})$ how the family attached meaning to the event and whether they enter or avert (X) crisis. This theory has been thoroughly tested and revised (e.g., Boss, 2002; Lavee, McCubbin, \& Patterson, 1985; McCubbin \& McCubbin, 1991) with more recent work focusing on the theory's application to the military marriage. Most recently, Boss (2002) expanded on the ABC-X Model by proposing internal and external contexts. The internal context includes things the family has control over and can change such as the structural, psychological, and philosophical domains. The external context includes things the family has no control over: culture, history, economy, development, and heredity. This contextual focus adds a much needed arena for focus on marital communication as integral in the process of surviving and thriving in the face of crisis.

Boss and others have continued to apply the $\mathrm{ABC}-\mathrm{X}$ model with its varied revisions and expansions to the military marriage. In Boss' proposed expansion of the theory to include internal and external contexts, the examples are focused in the military domain related to post-traumatic stress disorder (PTSD). Rosen and Durand (2000) have also further tested the ABC-X model with Persian Gulf War veterans. A two-phased study was commissioned, the first data collection was done while the service member was deployed and the second after the personnel had been stateside for one year. They conducted factor analysis and identified five factors that explained marital adjustment post-deployment: feeling distanced from each other; feeling closer to each other; increased role-sharing; increased independence of spouse; and increased dependence. They concluded that a large portion of the marriages that dissolved upon returning home had pre-deployment issues and that deployment actually strengthened the marriage for those who did not dissolve their marriages.

Despite the vast body of literature on marital satisfaction, available theories such as the ABC-X model continue to be weak in certain aspects. One area lacking, especially in relation to military marriages and deployment stress, is the impact of communication (Karney\& Crown, 2007) with the few studies on communication during deployment focusing heavily on the spouses, (i.e. Lapp, Taff, Tollefson, Hoepner, Moore, \& Divyak, 2010; Merolla, 2010; Sahlstein, Maguire, \& Timmerman, 2009) and only one from the veterans perspective (Durham, 2010). 
Partially in response to this, another theory of marital satisfaction was developed by Karney and Crown (2007) in their significant work Families under stress: An assessment of data, theory and research on marriage and divorce in the military. Karney and Crown (2007) drew upon literature studying civilian marriages to expand the stress hypothesis to fit within the context of a military marriage. Their theory has four components: (1) the conceptualization acknowledges the military spouses' enduring (i.e., items that are stable and each spouse brings to the marriage such as demographic, psychological, and personal history variables) and emergent traits (i.e., things that can change over the course of a marriage such as maturity or financial stability); (2) the consideration of the environmental factors within and outside the military community (e.g., family, employment, and housing); (3) the impact spousal communication has on the marriage; and (4) "that spouses' satisfaction with their marriage is but one predictor of whether or not a marriage will remain intact; barriers and a lack of alternatives can keep spouses in a marriage whether or not they find the marriage satisfying" (Karney \& Crown, 2007, p. xxvi-xxvii). How spouses communicate during deployment will impact the postdeployment marital outcome.

The Karney and Crown (2007) theory has been used to assist and guide other empirical investigations of military marital satisfaction (e.g., Allen, Rhoades, Stanley, \& Markman, 2010; Merolla, 2010). Allen et al. (2010) used the Karney and Crown (2007) framework to explain how adaptive processes such as communication contribute to the link between PTSD and marital satisfaction. They concluded that the adaptive processes such as communication outlined in Karney and Crown's model do partially account for the association between PTSD and marital satisfaction for both husbands and wives and note that focusing on communication is an important approach to intervention with couples struggling during post-deployment. Similarly, Merolla (2010) used Karney and Crown's model (2007) to guide their qualitative research on marital maintenance during deployment. Their study focused on spouses rather than service members and communication emerged as one of three main marriage maintenance mechanisms being not only important in terms of frequency but also in terms of mode of communication and the need for communication to be routinized.

\section{LITERATURE REVIEW}

Applewhite and Segal (1990) were among the first researchers to study modern modes of communication of military personnel during deployment. They surveyed 133 military personnel who were deployed on a peacekeeping mission to Sinai in the 1980s. The study concluded the majority of personnel thought optimistically about the use of the telephone as a medium to stay connected to family, but also found it to be extremely expensive. Interestingly, in their study of communication during Operation Restore Hope, Bell et al. (1999, p. 515) noted, "In general, communication had a positive effect on several outcome variables, with the notable exception of marital satisfaction, possibly operating through an intervening variable of perceived stressfulness of peacekeeping operations that was predicted by having had communication problems."

Sahlstein and colleagues (2009) conducted a qualitative investigation with a sample of 50 female spouses through the lens of relational dialectics. They found that through the 
different stages of deployment, several themes emerged: pre deployment (uncertainty vs. certainty), deployment (autonomy vs. connection), and post deployment (openness vs. closedness). They found military culture influences how spouses communicate in two ways. First, the soldier could not disclose information because of the operational security of the mission and secondly the variability in mode of communication. One participant specifically noted high-ranking officer's limited phone privileges as a consequence for unfavorable behavior in theatre.

Merolla (2010) conducted a qualitative investigation about marriage maintenance with 33 wives of currently deployed service members. His findings acknowledge geographic separation can help and hurt a relationship. The following modes of communication were the most frequently referenced in regards to communication with their spouse: phone (61\%), letters/care packages (55\%), email (including digital photos) (52\%), instant messenger/message board (15\%), video messages $(9 \%)$, and webcam (6\%). Participants had concerns about the military's operational security, meaning it limited the conversation on the phone and over the internet. Fifty-five percent of participants reported creating and maintaining a communication routine with family was important (Merolla, 2010).

Lapp et al. (2010) used a phenomenological perspective to guide their study. They interviewed 18 spouses (two were male) of National Guard and Reserve service members who lived in a rural or semi-rural setting of less than 70,000 people. The study found that some spouses felt captive to the instant forms of communication available-always waiting by the phone for their partner to call. Spouses intended to stay connected via telephone, instant messenger, email, and webcam. Lapp et al. (2010, p. 60) note "All of the participants were reassured by frequent contact with their spouse."

Most qualitative research has focused on the spouses of veterans who were deployed. Recently, Durham (2010) studied the service member's point of view by conducting a qualitative investigation of six OIF male combat veterans discharged from the military. She concluded that all respondents chose to limit their communication with family back home. Respondents report limiting their communication was done because of regulations, control, and the distraction it could cause from the mission. If a service member is distracted from the mission, it could led to less concentration resulting in death of self or a fellow service member.

Currently, little quantitative empirical investigation has been conducted on the impact of frequency and mode of communication during a combat deployment on marital satisfaction. These new modes of communication may act as potential confounding variables affecting marital satisfaction. With the ever-evolving modes of instant communication, these authors were interested in which mode would have the highest martial satisfaction. We suspect that internet-based communication will have the highest because it is immediate and allows for a more frequent routine whereas mail can take weeks to arrive at its destination and/or get misplaced. Additionally, these authors suspect that face-to-face communication via webcam will have higher marital satisfaction because it might provide a sense of comfort for the stateside spouse because they can visually see the service member. 
To date almost all the studies investigating communication within the marital dyad among OIF and OEF service members have been qualitative in nature. Previous researchers have laid a solid foundation for this quantitative investigation. A great deal of the current research pertaining to deployment and separation within a marital dyad is outcome driven (i.e., divorce or the marriage continues). Researchers (Drummet, Coleman, \& Cable, 2003; Merolla, 2010) assert relationship maintenance during deployment within the military community is an area that still needs further exploration. Karney and Crown (2007) posit current research is lacking in depth analysis about "all the ways that spouses interact, communicate, resolve problems, provide support, and understand each other" (p. 24). With only one empirical investigation primarily focusing on the service member (Durham, 2010), more studies are needed to understand things from their perspective.

The purpose of the current study was to explore the question: Is a service member's post-deployment marital satisfaction correlated with frequency and mode of communication during deployment? Three hypotheses guided the study, largely grounded in Merolla's study of marital maintenance from the spouses' perspective. Considering Merolla's (2010) work indicating that routine communication was an important factor in marital maintenance, the first hypothesis was that the higher the frequency of communication during deployment, the higher the marital satisfaction post-deployment. Since internet-based communication is more immediate than US mail and can be more frequent than the telephone, the second hypothesis was that participants who used internet-based communication during deployment will have higher post-deployment marital satisfaction scores than participants who used telephone and US mail. Finally, because communication and partner interaction emerged for the spouses in Merolla's study as major factors in marital maintenance, the third hypothesis was that participants who used face-to-face communication via webcam would have higher post-deployment marital satisfaction than participants who used other forms of internet-based communication.

\section{METHOD}

\section{Data Collection}

This exploratory study used an anonymous survey to investigate the relationship between spousal communication during deployment and marital satisfaction postdeployment. All procedures were approved by the University of Texas at Arlington Institutional Review Board. We contacted national veteran service and advocacy organizations through email to see if they would allow us to post a link to their private discussion boards, chat rooms, and send to their members. National service and advocacy organizations were selected based on how rigorously they vetted prospective members. Only organizations that verified eligibility through DD214s were allowed to participate in the survey. This was done to make sure the respondents were truly OIF/OEF veterans. After permission was obtained from the group leaders, they sent an email to their constituents or allowed us to post links on their websites, chat rooms, and discussion boards. Data was collected for approximately six weeks. 


\section{Instrumentation}

A researcher-developed survey was administered along with the Relationship Assessment Scale (RAS). The researcher-developed survey was designed to gather demographic information and inquire about frequency and mode of communication during deployment. The first question was "how often per week did you communicate with your spouse?" The possible answers were: less than once a week, 1-2 times a week, 3-4 times a week, 5-6 times a week, or every day. The second question was "what was the main mode of communication with your spouse while you were deployed?" The possible answers were: computer (email, instant messenger, and webcam), US mail, or telephone. If the respondent selected computer, a follow up question was administered, "what was the primary method of communication on the computer?" The possible answers were email, instant messenger/chat room, or webcam. For the questions about mode of communication, the respondents were allowed to only select one answer so as to ensure that we knew the main mode and primary method respectively.

The Relationship Assessment Scale (RAS) is a seven-item measure that assesses satisfaction in close relationships (Hendrick, 1988). The cumulative scores range from one to five. Hendrick, Dicke, and Hendrick (1998) report "Scores over 4.0 would likely indicate non-distressed partners, whereas scores closer to 3.5 for men and between 3.5 and 3.0 for women would indicate greater relationship distress and possibly substantial relationship dissatisfaction" (p. 141). The RAS has good discriminant validity (Hendrick, et al., 1998) and has been found to have good convergent validity with both the Dyadic Adjustment Scale (DAS) (.80 and .88) and the Kansas Marital Satisfaction Scale (KMSS) (.64 for men and .74 for women) (Hendrick, et al., 1998). Test-retest reliability of the RAS was .85 and it was found to be consistent across several samples (Hendrick, et al., 1998).

\section{Participants}

The sample consisted of 119 married participants. One hundred and one were males $(84.9 \%)$ and eighteen were females $(15.1 \%)$. Because there were only 18 females who responded, analyses were not conducted on the role of sex in terms of the research question. The majority were White $(89.9 \%)$. Four other categories accounted for the remaining 10.1\% (Hispanic, $n=4$; Other, $n=4$; More than one race, $n=3$; and African American, $\mathrm{n}=1$ ). Because there were only 12 non-Whites who responded, analyses were not conducted on the role of race and ethnicity in terms of the research question.

\section{Data Analysis}

The survey data were collected in categorical and continuous forms. The ordinal data were analyzed using nonparametric statistics - Spearman's Rank Correlation Coefficient, and the ratio data were analyzed using Analysis of Variance (ANOVA) using the Statistical Package for Social Sciences (SPSS) version 18.0. Statistical significance was assessed at both the .05 and .10 levels; the liberal .10 level is deemed acceptable for exploratory studies (Black, 1999). 


\section{RESULTS}

All 119 participants completed the Relationship Assessment Scale (RAS). The range of scores was from 1 to 5 with a mean of $3.65(\mathrm{SD}=1.02)$; the distribution approached normality. Higher scores indicate a non-distressed relationship. The primary mode of spousal communication was computer (email, instant messenger, webcam) $(55.5 \%)$ with telephone (24.4\%) and US mail (20.2\%) following. Please see Table 1 for a complete listing.

Table 1. Frequency of Communication with Spouse while Deployed

\begin{tabular}{|c|c|c|c|c|}
\hline $\begin{array}{l}\text { Mode of } \\
\text { Communication }\end{array}$ & $\begin{array}{l}\text { Frequency of } \\
\text { Communication }\end{array}$ & Frequency & Percent & $\begin{array}{r}\text { Cumulative } \\
\text { Percent }\end{array}$ \\
\hline \multirow{6}{*}{$\begin{array}{l}\text { Computer (email, } \\
\text { instant messenger, } \\
\text { webcam) }\end{array}$} & Less than once per week & 10 & 15.2 & \\
\hline & 1-2 times per week & 16 & 24.2 & \\
\hline & 3-4 times per week & 12 & 18.2 & \\
\hline & 5-6 times per week & 7 & 10.6 & \\
\hline & Everyday & 21 & 31.8 & \\
\hline & Total & 66 & 100.0 & 55.5 \\
\hline \multirow[t]{4}{*}{ US mail } & Less than once per week & 9 & 37.5 & \\
\hline & 1-2 times per week & 3 & 12.5 & \\
\hline & Everyday & 12 & 50.0 & \\
\hline & Total & 24 & 100.0 & 20.2 \\
\hline \multirow[t]{7}{*}{ Telephone } & Less than once per week & 5 & 17.2 & \\
\hline & 1-2 times per week & 8 & 27.6 & \\
\hline & 3-4 times per week & 2 & 6.9 & \\
\hline & 5-6 times per week & 3 & 10.3 & \\
\hline & Everyday & 11 & 37.9 & \\
\hline & Total & 29 & 100.0 & 24.4 \\
\hline & Grand Total & 119 & & 100.0 \\
\hline
\end{tabular}

\section{Hypothesis 1}

Hypothesis one is the higher the frequency of communication during deployment, the higher the marital satisfaction post-deployment. Since the frequency of communication was measured ordinally, Spearman's Rank Correlation Coefficient was calculated ( $\rho=$ $.238, \mathrm{p}<.01)$ and indicates a weak but statistically significant direct relationship. The average RAS score increased with frequency of communication. Those service members who communicated less than once per week while deployed had an average RAS score of 
3.34 whereas those who communicated everyday averaged 3.97. To assess whether the differences among means for the ordinal levels of frequency of communication were statistically significant, an Analysis of Variance (ANOVA) was conducted. It was statistically significant $\left(\mathrm{F}_{(118)}=2.18, \mathrm{p}=.08\right)$ at the .10 level of significance. Please see Table 2 for frequency of communication and mean RAS scores.

Table 2. Mean Frequency of Communication with Spouse when Service Member was Deployed and Average RAS Score

\begin{tabular}{lccr}
\hline Frequency of Communication & N & Mean & Std. Dev. \\
\hline Less than once per week & 24 & 3.34 & 1.19 \\
1-2 times per week & 27 & 3.46 & 1.14 \\
3-4 times per week & 14 & 3.45 & 1.09 \\
5-6 times per week & 10 & 3.84 & .59 \\
Everyday & 44 & 3.97 & .82 \\
Total & 119 & 3.65 & 1.02 \\
\hline
\end{tabular}

\section{Hypothesis 2}

Hypothesis two is that participants who used internet-based communication during deployment will have higher post-deployment marital satisfaction scores than participants who used telephone and US mail. The average RAS score differed with mode of communication. Those service members who preferred internet-based communication (email, instant messenger, webcam) had an average RAS score of $3.50(\mathrm{SD}=1.08)$, US mail $4.10(\mathrm{SD}=.63)$, and telephone $3.64(\mathrm{SD}=1.06)$. The Analysis of Variance (ANOVA) was statistically significant $\left(\mathrm{F}_{(116)}=3.20, \mathrm{p}<.05\right)$ at the .05 level of significance.

\section{Hypothesis 3}

Participants who used face-to-face communication via webcam would have higher post-deployment marital satisfaction than other forms of internet-based communication. The Analysis of Variance (ANOVA) was not statistically significant $\left(\mathrm{F}_{(63)}=1.73, \mathrm{p}=\right.$ .19). Please see Table 3 for means and standard deviations.

Table 3. Type of Computer Communication and Average RAS Score

\begin{tabular}{lrrr}
\hline Method of Computer Communication & N & Mean & Std. Dev. \\
\hline Email & 55 & 3.59 & 1.03 \\
Instant messenger or chat room & 7 & 2.80 & 1.03 \\
Webcam & 4 & 3.43 & 1.67 \\
Total & 66 & 3.50 & 1.08 \\
\hline
\end{tabular}




\section{DISCUSSION}

The purpose of this study was to explore the question: Is a service member's postdeployment marital satisfaction correlated with frequency and mode of communication during deployment? This study expands the current literature to include quantitative analysis of the topic since the previous research on communication during a combat deployment has been overwhelmingly qualitative (e.g. Durham, 2010; Lapp, et al., 2010; Merolla, 2010; Sahlstein, et al., 2009). This study also depicts the veterans' experiences since three of the previous studies used samples of spouses (i.e. Lapp, et al., 2010; Merolla, 2010; Sahlstein, et al., 2009), and only Durham's (2010) used a small sample of veterans.

Findings include that the higher the frequency of communication during deployment, the higher the marital satisfaction post-deployment for the veteran. This supports the theory of military marriage presented by Karney and Crown (2007) where communication is one of four aspects contributing to whether a marriage survives stressors such as combat deployment. This is in contrast to a previous empirical investigation that found communication during Operation Restore Hope did not impact marital satisfaction (Bell et al., 1999). However, it should be noted that Operation Restore Hope did not have the years of infrastructure that a deployed service member now enjoys in OIF or OEF. It is reasonable to consider that since the infrastructure is more comprehensive in OIF and OEF soldiers have access to more reliable communication, which Bell et al. (1999) listed as a possible reason communication did not have a positive impact on marital satisfaction.

Additionally, researchers found that despite the wider availability of new technologies (e.g. webcam, email, synchronous chat) for communicating during deployment, US mail was still the most highly correlated with level of marital satisfaction post-deployment. Of the internet-based forms of communication, email produced the highest RAS scores $(\mathrm{M}=3.59)$ over synchronous forms of communication (i.e. chat and webcam).

There are a plethora of possible reasons why US mail was related to higher RAS scores than internet-based communication and the telephone, all likely connected to another component of Karney and Crown's (2007) theory of stress as it relates to military marriage: the consideration of the environmental factors within and outside the military community (i.e., family, employment, and housing). In general the instant nature of these types of communication has its drawbacks. Lapp et al. (2010) noted that some spouses stateside felt bound to their mode of communication always waiting by the phone for their partner to call. Spouses may also be more apt to vent frustrations in an unfettered way whereas letter writing allows time for the spouse to reflect on the most important things to focus on in communication. Instant communication also presents issues for the service member. Deployed service members try to limit their communication with loved ones stateside because they believe it could take away from the mission (Durham, 2010), interfering with concentration and focus which could end up in them not doing their job to their best ability resulting in a person's death, possibly their own. 
Another reason for US mail's continuing preferential status among service members may be related to cost, time and location constraints when using telephones and the internet. Though there are many veteran friendly organizations that provide free calling cards to deployed service members, the cost of sending a letter via US mail or email or chatting online is far less than using the telephone while deployed. Time constraints are another issue for the telephone as well as the internet. While letters can be written anywhere and anytime, the internet and telephones require equipment often shared with many fellow-service members requiring scheduling. With shared equipment, scheduling usage is not the only issue. Location is perhaps the most important since telephones and internet are usually accessed in community settings. There is likely an element of closeness that can be delivered in a hand written letter that cannot be in an email or a phone conversation. Spouses may feel at liberty to write more personal information in a letter that they think no one else could look at since letters can be written in fairly private settings.

Related to privacy are deployed service members' concerns about operational security (Merolla, 2010) which can be easily compromised if the enemy is monitoring internet-based correspondence. Service members might feel at greater liberty to say things in a letter than through internet-based communication or over the telephone because of operational security. A letter that is sealed in an envelope will not face the security scrutiny internet-based or telephone communication would.

\section{Limitations}

This study did have limitations with regard to sampling, questions asked, and choice of method. In terms of sampling, limitations were: 1) we only collected data from the service member and not the spouse; 2) we limited the study to service members who were still married at the time of the survey possibly creating a bias toward higher marital satisfaction; 3) the sample was mostly White. We recommend that future researchers include the spouses as participants and aim for a more diverse sample on relationship status (i.e., include divorced and separated), race, and ethnicity. Though the sample seems heavily biased toward Whites, our sample is very closely representative of the military dispersion of race as indicated in Table 4 which notes how our sample compares to the target population. For the questions asked, our two main limitations were: 1) we did not focus on the content of the correspondence, only the frequency; and 2) we did not ask the participants about availability of modes of communication during deployment nor command restrictions on frequency of communication. Future studies should attempt to incorporate a mixed methods approach. The quantitative element should be structured to capture the method and frequency of communication and the limitations to these in terms of availability and command limitations to frequency. The qualitative piece should be designed to incorporate the content of the communication especially to determine if there is closeness that is delivered in a letter that is not in internet or telephone communication due to operational security concerns. 
Table 4. Study Sample Demographics Compared to US Military Active Duty 2008 Demographics

\begin{tabular}{|c|c|c|}
\hline & Study Sample & $\begin{array}{l}\text { Target Population (Active Duty US } \\
\text { Military as of 2008) }\end{array}$ \\
\hline \multirow[t]{2}{*}{$\operatorname{Sex}^{\mathrm{a}}$} & Male $=85 \%$ & $\begin{array}{l}\text { Male }(\text { Officers })=85 \% \\
\text { Male }(\text { Enlisted })=86 \%\end{array}$ \\
\hline & Female $=15 \%$ & $\begin{array}{l}\text { Female }(\text { Officers })=15 \% \\
\text { Female }(\text { Enlisted })=14 \%\end{array}$ \\
\hline $\operatorname{Age}^{a}$ & 36.35 years old & 28 years old \\
\hline Race $^{a, b}$ & $\begin{array}{l}\text { White }=90 \% \\
\text { All others }=10 \%\end{array}$ & $\begin{array}{l}\text { White }=75 \% \\
\text { All others }=25 \%\end{array}$ \\
\hline Married $^{\text {a }}$ & $100 \%$ & $55 \%$ \\
\hline \multicolumn{3}{|c|}{$\begin{array}{l}\text { a Defense Manpower Data Center (DMDC) (2008). Active Duty Demographic Profile. Retrieved from } \\
\text { www.deomi.org/home/saveCountFiles.cfm?fileid=280. }\end{array}$} \\
\hline
\end{tabular}

\section{Implications for Social Work Practice}

Concerns for the safety of the service member and his or her fellow-service members, privacy, and security of the mission must be considered in tandem with the study results that frequent communication correlates with happier marriages post-deployment. Specific implications for social work practice relate to actions to be taken both with the soldier and the spouse. Prior to deployment, it is recommended that soldiers and their spouses be encouraged to use hand-written letters as their primary form of communication with each other, limiting internet and phone usage to quick messages of love and greeting, explaining the body of literature supporting that hand-written letters strengthen the marriage. Perhaps the couple could agree to write a few sentences to each other every day and mail the result every few days. Both soldiers and spouses should be encouraged to consider the impact of words on the others' well-being, knowing that news of the others sadness or other difficulties could compromise the soldier's safety or the spouse's coping with the soldier's absence, respectively. If both soldier and spouse are able to focus on the positive - especially positive emotions - in their communication (regardless of mode), outcomes will include increased positive emotions, resilience and improved quality of life (Frederickson, 2001). During deployment, it is recommended for nonprofits that typically have assisted with telephone access through calling cards and cell phones focus their efforts more on care packages, stationary, postage, and the like. Not only will this encourage use of US mail but will also allow their limited funds to stretch further, helping more soldiers and spouses than previous phone-focused endeavors. 


\section{References}

Allen, E. S., Rhoades, G. K., Stanley, S. M., \& Markman, H. J. (2010). Hitting home: Relationships between recent deployment, posttraumatic stress symptoms, and marital functioning for Army couples. Journal of Family Psychology, 24(3), 280-288.

Applewhite, L. W., \& Segal, D. R. (1990). Telephone use by peacekeeping troops in the Sinai. Armed Forces \& Society, 17(1), 117-126.

Bell, D. B., Schumm, W. R., Knott, B., \& Ender, M. G. (1999). The Desert Fax: A research note on calling home from Somalia. Armed Forces \& Society, 25(3), 509521.

Black, T. R. (1999). Doing quantitative research in the social sciences: An integrated approach to research design, measurement and statistics. London: Sage.

Boss, P. (2002). Family stress management: A contextual approach $\left(2^{\text {nd }} \mathrm{ed}\right.$.). Thousand Oaks, CA: Sage Publications.

Defense Manpower Data Center. (DMDC). (2008). Active Duty Demographic Profile. Retrieved from www.deomi.org/home/saveCountFiles.cfm?fileid=280.

Drummet, A. R., Coleman, M., \& Cable, S. (2003). Military families under stress: Implications for family life education. Family Relations, 52, 279-287.

Durham, S. W. (2010). In their own words: Staying connected in a combat environment. Military Medicine, 175(8), 554-559.

Ender, M. G., \& Segal, D. R. (1990). V (E)-mail to the foxhole: Soldier isolation, (tele)communications, and force-projection operations. Journal of Political and Military Sociology, 24(1), 83-104.

Fredrickson, B. L. (2001). The role of positive emotions in positive psychology: The broaden-and-build theory of positive emotions. American Psychologist, 56, 218-226.

Hendrick, S. S. (1988). A generic measure of relationship satisfaction. Journal of Marriage and the Family, 50, 93-98.

Hendrick, S. S., Dicke, A., \& Hendrick, C. (1998). The relationship assessment scale. Journal of Social and Personal Relationships, 15(1), 137-142.

Hill, R. (1958, February/March). Generic features of families under stress. Social Casework, 49, 139-150.

Karney, B. R., \& Crown, J. S. (2007). Families under stress: An assessment of data, theory, and research on marriage and divorce in the military. Santa Monica, CA: RAND.

Lapp, C. A., Taft, L. B., Tollefson, T., Hoepner, A., Moore, K., \& Divyak, K. (2010). Stress and coping on the home front: Guard and Reserve spouses searching for a new normal. Journal of Family Nursing, 16(1) 45-67. Doi: 10.1177/1074840709357347 
Lavee, Y., McCubbin, H. I., \& Patterson, J. (1985). The double ABCX model of family stress and adaptation: An empirical test by analysis of structural equations with latent variables. Journal of Marriage and the Family, 47, 811-825.

McCubbin, M. A., \& McCubbin, H. I. (1991). Family stress theory and assessment: The resiliency model of family stress, adjustment, and adaptation. In H. I. McCubbin \& A. I. Thompson (Eds.), Family assessment inventories for research and practice (pp. 3-32). Madison, WI: The University of Wisconsin-Madison.

Merolla, A. J. (2010). Relational maintenance during military deployment: Perspectives of wives of deployed US soldier. Journal of Applied Communication Research, 38(1), 4-26. Doi: 10.1080/00909880903483557

Rosen, L. N., \& Durand, D. B. (2000). Marital adjustment following deployment. In J. A. Martin, L. N. Rosen, \& L. R. Sparacino (Eds.), The military family: A practice guide for human service providers (pp. 153-165). Westport, CT: Praeger.

Sahlstein, E., Maguire, K. C., \& Timmerman L. (2009). Contradictions and praxis contextualized by wartime deployment: Wives' perspectives revealed through relational dialectics. Communication Monographs, 76(4), 421-442.Doi: $10.1080 / 03637750903300239$

Schumm, W. R., Bell, D. B., Ender, M. G., \& Rice, R. E. (2004) Expectations, use, and evaluation of communication media among deployed peacekeepers. Armed Forces \& Society, 30(4), 649-662.

Stouffer, S. A., Suchman, E. A., DeVinney, L. C., Star, S. A., \& Williams, Jr., R. M. (1949). Studies in social psychology in World War II: The American Soldier. Vol. 1, Adjustment during Army life. Princeton: Princeton University Press.

\section{Author's note:}

Address correspondence to: Regina T. P. Aguirre, PhD, Assistant Professor, The University of Texas at Arlington School of Social Work, 211 S. Cooper, Box 19129, Arlington, TX 76019, rtpaguirre@uta.edu. 